\title{
Long-term outcomes of colorectal endoscopic submucosal dissection in elderly patients
}

\author{
Yoshifumi Takahashi $^{1} \cdot$ Ken-ichi Mizuno $^{1} \cdot$ Kazuya Takahashi $^{1} \cdot$ Hiroki Sato $^{1} \cdot$ \\ Satoru Hashimoto ${ }^{1}$ - Manabu Takeuchi ${ }^{2}$. Masaaki Kobayashi ${ }^{3} \cdot$ Junji Yokoyama $^{1}$. \\ Yuichi Sato $^{1} \cdot$ Shuji Terai ${ }^{1}$
}

Accepted: 18 November 2016/Published online: 30 November 2016

(C) The Author(s) 2016. This article is published with open access at Springerlink.com

\begin{abstract}
Background and aims The safety and efficacy of endoscopic submucosal dissection (ESD) in elderly patients remain unclear. The aim of this study is to clarify the short- and long-term outcomes of colorectal ESD in elderly patients.

Patients and methods A total of 482 consecutive patients with 501 colorectal lesions treated with ESD from February 2005 to December 2013 were retrospectively reviewed. Patients were divided into two groups: an elderly group ( $\geq 75$ years of age) and a non-elderly group ( $<75$ years of age). Shortterm outcomes of interest were procedure time, complication rate, hospital stay, en bloc resection rate, and non-curative resection rate. Long-term outcomes of interest were diseasespecific survival, and overall survival rates in the elderly group (51 patients) and non-elderly group (92 patients) were also analyzed.

Results No significant differences were observed between the groups with respect to short-term outcomes. Two patients in each group required emergency surgery. Of the patients who underwent non-curative resection, $7 / 12(58 \%)$ in the elderly group and $15 / 23(65 \%)$ in
\end{abstract}

Yoshifumi Takahashi

ytty0125ytty@yahoo.co.jp

1 Graduate School of Medical and Dental Science, Department of Gastroenterology and Hepatology, Niigata University, 757-1, Asahimachidori, Chuo-ku, Niigata City, Niigata 951-8510, Japan

2 Department of Gastroenterology and Hepatology, Nagaoka Red Cross Hospital, Nagaoka, Japan

3 Department of Gastroenterology and Hepatology, Uonuma Institute of Community Medicine, Niigata University Medical and Dental Hospital, Niigata, Japan the non-elderly group underwent additional surgery. The 5-year disease-specific survival rates in the elderly and non-elderly groups were both $100 \%$, and the corresponding 5-year overall survival rates were 86.3 and $93.5 \%$, respectively $(p=0.026)$.

Conclusions Short-term outcomes after colorectal ESD were equivalent in both groups, and all patients showed favorable long-term outcomes. Considering the benign prognosis of lesions resected with ESD, preoperative screening of comorbidities is essential to improve overall survival.

Keyword Colorectal cancer $\cdot$ Elderly $\cdot$ Endoscopic submucosal dissection

\section{Introduction}

The aging of the global population is a worldwide problem and has a significant effect on clinical practice [1]. In Japan, there has also been an increase in the number of elderly citizens, and the proportion of people aged older than 75 years reached $12.9 \%$ in 2015 [2]. Elderly patients usually present with comorbidities; therefore, indications for surgical treatment based on age have traditionally been debated $[3,4]$.

Colorectal cancer (CRC) is one of the most common diseases in the elderly, and the incidence of CRC has been rapidly increasing in Asian and Western countries. While surgical resection is the main treatment for CRC, this method may not be appropriate or safe in elderly patients with comorbidities. Meanwhile, endoscopic resection has been developed as a minimally invasive procedure for early $\mathrm{CRC}$ and precancerous lesions. Endoscopic submucosal dissection (ESD) has become widespread because of its high en bloc resection rate. However, ESD is not without its complications, which include a risk of perforation and bleeding [5-8]. The increasing 
incidence of CRC has led to the increased use of ESD procedures in elderly patients. However, few reports have discussed ESD in the elderly $[9,10]$. In the present study, we aimed to assess the safety and efficacy of ESD in elderly patients, and investigated age-specific differences in short- and long-term outcomes following ESD.

\section{Materials and methods}

A total of 482 consecutive patients with 501 colorectal lesions treated with ESD at the Niigata University Medical and Dental Hospital from February 2005 to December 2013 were retrospectively reviewed. All lesions were observed via magnifying chromoendoscopy before the ESD procedure [11, 12]. The indications for colorectal ESD were as follows: estimated depth of submucosal invasion of less than $1000 \mu \mathrm{m}$, tumor size larger than $20 \mathrm{~mm}$, or tumor less than $20 \mathrm{~mm}$ in diameter showing non-lifting signs.

The patients were divided into two groups: an elderly group consisting of patients $\geq 75$ years of age and a nonelderly group consisting of patients $<75$ years of age. Tumor size, procedure time, complication rate (perforation and bleeding), hospital stay, en bloc resection rate, non-curative resection rate, and management of non-curative resection cases were compared between these two groups.

\section{ESD procedure}

Bowel irrigation was performed with 2-3 L of polyethylene glycol solution before the procedure. ESD was performed using a single-channel gastrointestinal endoscope (Olympus PCF TYPE Q260AI or PCF TYPE Q260JI, Olympus Medical Systems, Co. Ltd., Tokyo, Japan) and a high-frequency generator with an automatically controlled system (ICC200 or VIO300D, Erbe Elektromedizin Ltd., Tübingen, Germany). The solution for submucosal injection was a mixture of $10 \%$ glycerol and epinephrine. When long-lasting elevation of the submucosa was required, hyaluronic acid solution (Mucoup; Johnson \& Johnson K.K., Tokyo, Japan) was injected [13, 14]. The DualKnife (KD-650Q, Olympus Medical Systems Co. Ltd.), HookKnife (KD620QR, Olympus Medical Systems Co. Ltd.), and FlushKnife (DK2618JN20, Fujinon Co., Tokyo, Japan) insulated tip knives were used for ESD, and the Coagrasper (FD-411QR, Olympus Medical Systems Co. Ltd.) was used for coagulation and hemostasis. Intravenous midazolam or dexmedetomidine hydrochloride was administered during all ESD procedures. Carbon dioxide insufflation was used during all ESD procedures instead of air insufflation to reduce patient discomfort as well as gas leakage in the case of an intraoperative perforation.

\section{Histopathological assessment}

All resected specimens were fixed in $10 \%$ buffered formalin and cut into 2-mm slices. Hematoxylin-eosinstained sections were histopathologically examined by pathologists in our hospital. The criteria for curative resection were as follows: the lateral and vertical margins of the specimen were free of cancer, submucosal invasion was less than $1000 \mu \mathrm{m}$ from the muscularis mucosae, there was no evidence of lymphatic or vascular invasion, and there were no poorly differentiated components. Histological diagnoses were based on the Japanese classification system for cancer of the colon and rectum and the Vienna classification system [15].

\section{Follow-up and collection of long-term outcome data}

Follow-up surveillance endoscopy was performed 612 months after ESD. Annual surveillance endoscopies and contrasted-enhanced computed tomography (CT) scans were scheduled for patients with non-curative resections.

The long-term outcome data of patients who underwent colorectal ESD were collected retrospectively from January 2014 to March 2014. Patients who underwent colorectal ESD from February 2005 to December 2008 were enrolled in the analysis of long-term outcomes. For patients who had not visited our hospital regularly, the long-term outcome data were retrieved by request from the referring physicians, or through a mail questionnaire or structured telephone interview. Survival time was calculated as the interval between the date of the first treatment and the date of death or the last date on which the patient was confirmed to be alive. This study was approved by the ethics committee of the school of medicine, Niigata University, Japan. Written informed consent to participate was obtained from all patients who underwent colorectal ESD.

\section{Statistical analysis}

All variables in this study were analyzed with the SPSS version 17 software (SPSS Japan Inc., Tokyo, Japan). The variables between the two groups were analyzed with independent Student's $t$ test or Mann-Whitney $U$ test. A $\chi 2$ test and Fisher's exact test were performed for categorical variables. Overall survival rates were calculated by using the KaplanMeier method with comparison between the groups using the log-rank test. All tests of significance were two-tailed, and $p$ values $<0.05$ were considered statistically significant. 


\section{Results}

\section{Patient characteristics and lesions}

A total of 482 consecutive patients with 501 colorectal lesions were treated with ESD. Of these, 157 were in the elderly group (mean age 79.3 years, range $75-90$ ), and 325 were in the nonelderly group (mean age 63.9 years, range 27-74). Patient characteristics are summarized in Table 1. There were no significant differences between the two groups with respect to sex ratio, tumor location, tumor size, or morphology. A total of 11 lesions in the elderly group and 19 in the non-elderly group were diagnosed on histopathology as deep invasive submucosal cancer. There were no significant differences in the histopathological assessments.

\section{Short-term outcomes of colorectal ESD}

A comparison of short-term outcomes following ESD in each group is summarized in Table 2. The mean procedure times were $117 \mathrm{~min}$ (range 20-450) in the elderly group and 112 min (range 10-525) in the non-elderly group. There was no significant difference in procedure time. The en bloc resection rates were $96.3 \%$ in the elderly group and $93.4 \%$ in the non-elderly group. The non-curative resection rate in the

Table 1 Patient and tumor characteristics

\begin{tabular}{|c|c|c|c|}
\hline & $\begin{array}{l}\text { Elderly } \\
\text { patients }\end{array}$ & $\begin{array}{l}\text { Non-elderly } \\
\text { patients }\end{array}$ & $p$ value \\
\hline Patients $(n)$ & $157(32.6 \%)$ & $325(67.4 \%)$ & \\
\hline Age (years), mean (range) & $79.3(75-90)$ & $63.9(27-74)$ & \\
\hline Sex, male/female & $92 / 65$ & $197 / 128$ & 0.67 \\
\hline Lesion $(n)$ & $164(32.7 \%)$ & $337(67.3 \%)$ & \\
\hline \multicolumn{4}{|l|}{ Tumor location $(n)$} \\
\hline Cecum and colon & $112(68.3 \%)$ & $227(67.4 \%)$ & \multirow[t]{2}{*}{0.83} \\
\hline Rectum & $52(31.7 \%)$ & $131(32.6 \%)$ & \\
\hline \multicolumn{4}{|l|}{ Tumor size } \\
\hline Long axis $(\mathrm{mm})$, mean $\pm \mathrm{SD}$ & $37.0 \pm 16.5$ & $35.2 \pm 15.9$ & 0.26 \\
\hline Short axis $(\mathrm{mm})$, mean $\pm \mathrm{SD}$ & $29.7 \pm 15.4$ & $27.7 \pm 13.6$ & 0.23 \\
\hline \multicolumn{4}{|l|}{ Morphology $(n)$} \\
\hline LST-G & $93(56.7 \%)$ & $173(51.3 \%)$ & \multirow[t]{5}{*}{0.68} \\
\hline LST-NG & $55(33.5 \%)$ & $122(36.2 \%)$ & \\
\hline Protruded & $14(8.5 \%)$ & $34(10.1 \%)$ & \\
\hline Depressed & $0(0.0 \%)$ & $2(0.6 \%)$ & \\
\hline Residual/local recurrence & $2(1.2 \%)$ & $6(1.8 \%)$ & \\
\hline \multicolumn{4}{|l|}{ Histological classification $(n)$} \\
\hline Adenoma & $52(31.7 \%)$ & $131(38.9 \%)$ & \multirow[t]{6}{*}{0.47} \\
\hline Intramucosal cancer & $89(54.3 \%)$ & $164(48.7 \%)$ & \\
\hline SM superficial cancer & $11(6.7 \%)$ & $20(5.9 \%)$ & \\
\hline SM deep cancer & $11(6.7 \%)$ & $19(5.6 \%)$ & \\
\hline Others & $0(0.0 \%)$ & $2(0.6 \%)$ & \\
\hline Failure of retrieval & $1(0.6 \%)$ & $1(0.3 \%)$ & \\
\hline
\end{tabular}

Table 2 Short-term outcomes of colorectal ESD

\begin{tabular}{llll}
\hline & $\begin{array}{l}\text { Elderly } \\
\text { patients }\end{array}$ & $\begin{array}{l}\text { Non-elderly } \\
\text { patients }\end{array}$ & $p$ value \\
\hline $\begin{array}{l}\text { Procedure time (min), } \\
\text { mean (range) }\end{array}$ & $117(20-450)$ & $112(10-525)$ & 0.12 \\
En bloc resection rate & $96.3 \%$ & $93.4 \%$ & 0.18 \\
Non-curative resection rate & $7.4 \%$ & $6.8 \%$ & 0.82 \\
$\begin{array}{l}\text { Hospital stay (day), } \\
\text { mean (range) }\end{array}$ & $7.5(5-32)$ & $7.8(4-27)$ & 0.37 \\
Complication rate (overall) & $9.8 \%(16 / 164)$ & $6.8 \%(23 / 337)$ & 0.25 \\
Intraoperative perforation & $6.1 \%(10 / 164)$ & $5.9 \%(20 / 337)$ & 0.94 \\
Postoperative bleeding & $3.0 \%(5 / 164)$ & $0.9 \%(3 / 337)$ & 0.07 \\
Delayed perforation & $0.6 \%(1 / 164)$ & $0.0 \%(0 / 337)$ & 0.15 \\
Emergency surgery & $1.2 \%(2 / 164)$ & $0.5 \%(2 / 337)$ & 0.46 \\
Cause for emergency & & & \\
$\quad$ surgery $(n)$ & & 1 & \\
$\quad$ Intraoperative perforation & 0 & 0 & \\
$\quad \begin{array}{l}\text { Delayed perforation } \\
\text { Postoperative bleeding }\end{array}$ & 1 & 0 & \\
$\quad$ Intraoperative bleeding & 0 & 1 & \\
\hline
\end{tabular}

elderly group was $7.4 \%$, while the rate in the non-elderly group was $6.8 \%$. There were no significant differences in the en bloc resection rates, non-curative resection rates, and hospital stay lengths between the two groups. Intraoperative perforation and postoperative bleeding rates in the elderly group were 6.1 and $3.0 \%$, respectively, and corresponding values in the non-elderly group were 5.9 and $0.9 \%$. There was one case of delayed perforation in the elderly group $(0.6 \%)$. The elderly group showed a slightly higher postoperative bleeding rate; however, there was no statistically significant difference. During the study period, four cases with severe complications required emergency surgery. There were no significant differences in the rates of overall complications or emergency surgeries between groups. Of the patients who underwent noncurative resections, five in the elderly group and eight in the non-elderly group were carefully followed without additional treatment. The proportions of patients who required additional surgery were not significantly different between the two groups (Table 3).

\section{Long-term outcomes of endoscopic submucosal resection}

Among all patients, 51/53 (96.2\%) in the elderly group and $92 / 105(87.6 \%)$ in the non-elderly group were enrolled in long-term analysis after exclusion of follow-up losses (Fig. 1). There was no significant difference in follow-up rates $(p=0.08)$. Median follow-up duration of the elderly and nonelderly groups was 70.6 and 75.4 months, respectively. Local recurrence was found in one case (2.0\%) in the elderly group in which a piecemeal resection was performed. 
Table 3 Management of patients who underwent non-curative resection

\begin{tabular}{llll}
\hline & $\begin{array}{l}\text { Elderly } \\
\text { patients }\end{array}$ & $\begin{array}{l}\text { Non- } \\
\text { elderly } \\
\text { patients }\end{array}$ & $p$ value \\
\hline Additional surgery $(n)$ & $7 / 12$ & $15 / 23$ & 0.69 \\
Residual lesions $(n)$ & $4 / 7$ & $3 / 15$ & \\
Lymph node & $1 / 7$ & $4 / 15$ & \\
$\quad$ metastasis $(n)$ & & $0 / 23$ & \\
Distant metastasis $(n)$ & $0 / 12$ & $8 / 23$ & \\
Careful follow-up $(n)$ & $5 / 12$ & &
\end{tabular}

\section{Five-year disease-specific survival and overall survival}

No disease-specific deaths were noted during the follow-up period. All-cause death was reported in nine patients in the elderly group (17.6\%) and nine patients in the non-elderly group $(9.8 \%)$. The causes of death are summarized in Table 4. Among the causes of death, several types of neoplasms (e.g., lung, liver, stomach, breast, and brain) occurred in both groups. In the elderly group, three patients (33.3\%) died of old age. By contrast, three patients $(33.3 \%)$ died from accidents in the non-elderly group. Figure 2 illustrates the disease-specific and overall survival curves for both groups. The 5-year overall survival rates were $86.3 \%$ in the elderly group and $93.5 \%$ in the non-elderly group $(p=0.026)$.

\section{Discussion}

This study compared short-term and long-term outcomes of colorectal ESD in elderly and non-elderly patients. Safe and effective short-term outcomes of colorectal ESD have been previously reported by several investigators [5-8]. However, few studies have addressed age-specific differences in shortterm outcomes $[9,10]$. Perforation is one of the complications that could cause a severe adverse event. Several studies have reported that tumor size, morphology, location, and procedure time were important factors associated with intraoperative
Table 4 Cause of death during long-term follow-up

\begin{tabular}{lll}
\hline Cause of death & $\begin{array}{l}\text { Elderly patients } \\
(n=9 / 51)\end{array}$ & $\begin{array}{l}\text { Non-elderly patients } \\
(n=9 / 92)\end{array}$ \\
\hline Lung cancer & 1 & 1 \\
Liver cancer & 2 & 1 \\
Gastric cancer & 1 & 1 \\
Breast cancer & & 1 \\
Brain tumor & & 1 \\
Heart attack & 1 & \\
Renal insufficiency & 1 & \\
Pneumonia & 3 & 3 \\
Died of old age & 1 & \\
Accident & &
\end{tabular}

perforation [16-18]. Regarding patient and lesion characteristics in this study, there were no differences between the two groups except for age. This meant that neither of the two groups had specific risk factors for intraoperative perforation. Intraoperative perforation rates in the elderly and non-elderly groups in our study were 6.1 and $5.9 \%$, respectively. A multicenter questionnaire survey in Japan by Taku et al. [19] and a multicenter study by Tanaka et al. [20] reported that the overall perforation rate of colorectal ESD was 4.8 and $14 \%$, respectively, and these values were comparable to those in our study. Moreover, there was no significant difference in the perforation rates of the two groups. Delayed perforation is a rarer complication than intraoperative perforation that requires emergency surgery [20]. In this study, one case of delayed perforation occurred in the elderly group $(2.0 \%)$. The risk factors for delayed perforation remain unclear because of the small number of cases published, and therefore further investigation into these risk factors is required.

Bleeding is a common complication of ESD. Most bleeding was generally controllable by using hemostatic devices. However, in this study, there was one case of uncontrollable intraoperative bleeding and one case of postoperative bleeding which required emergent surgeries. Predictive factors for these
Fig. 1 Inclusion of patients in the analysis to evaluate long-term outcomes after colorectal endoscopic submucosal resection (ESD)
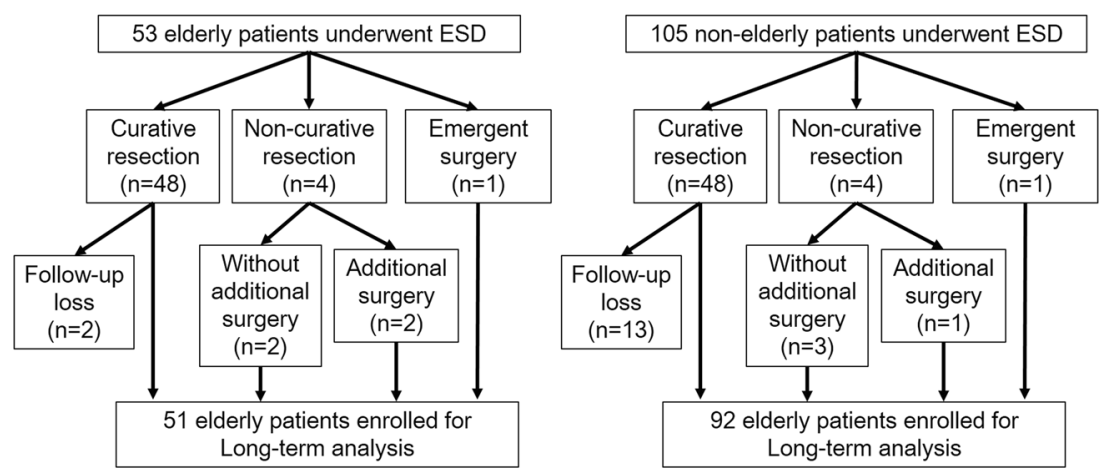
a

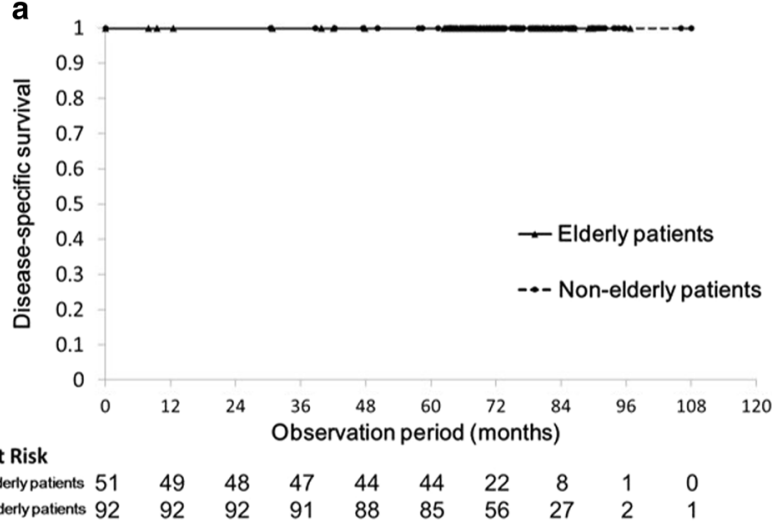

b

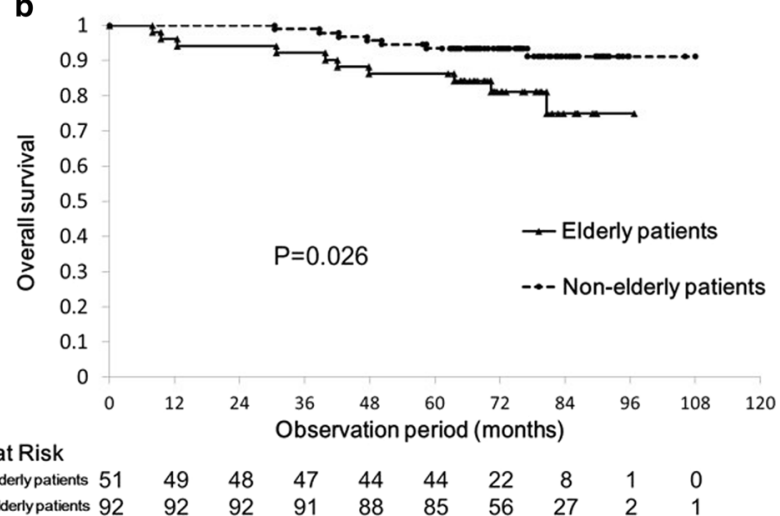

Fig. 2 a Estimated disease-specific survival curves for the elderly and non-elderly groups. b Estimated overall survival curves for the elderly and non-elderly groups. The solid line indicates the survival curve of the elderly group, whereas the dotted line shows that of the non-elderly group

complications should be clarified by further investigation to ensure safe ESD procedures.

The mean lengths of hospital stay of patients in the elderly and non-elderly groups were 7.5 and 7.8 days, respectively. In our hospital, all patients were admitted on the day before ESD, so the mean hospital stays after ESD in each group were approximately 5 days. Other studies of colorectal ESD reported similar hospital stays [9, 10]. Duration of hospital stay may be a surrogate indicator of postoperative morbidity. There was no significant difference in the length of hospital stays between the two groups; thus, ESD is a well-tolerated procedure for both elderly and non-elderly patients.

Among the patients who underwent non-curative resections, $7 / 12(58 \%)$ in the elderly group and $15 / 23(65 \%)$ in the non-elderly group underwent additional surgeries. A previous study reported that the ratio of patients who underwent additional surgeries was lower in elderly patients than younger patients; the reasons for avoiding additional surgery included the low mortality rates for surgery and requests of patients and families [10]. In the current study, the ratio of additional surgeries in the elderly group was slightly lower than in the nonelderly group, but this difference was not statistically significant. According to recent reports, laparoscopic surgery for colorectal cancer shows favorable short-term outcomes in elderly patients as well as in younger patients [21-24]. Recently, most of the additional surgeries have been performed through a laparoscope in our hospital. Therefore, the ratio of elderly patients who undergo additional surgery may be increasing.

Few previous studies have reported the long-term outcomes of patients who underwent colorectal ESD [25, 26]. Niimi et al. [25] reported that the 3-year disease-specific and overall survival rates were 100 and $97.1 \%$, respectively, and the corresponding 5-year values were 100 and $95.3 \%$, respectively. Cong et al. [26] reported similar long-term outcomes of patients with laterally spreading tumors. The median followup duration in previous reports was approximately 3 years, whereas patients in our study were followed up for a longer period of time. In addition, this study showed favorable disease-specific survival rates that were comparable to those cited in previous reports. This means that our data provide further support for the benign prognosis of the colorectal lesions resected by ESD. On the other hand, the current study is the first to report age-specific long-term outcomes after colorectal ESD. The non-elderly group showed better overall survival than the elderly group, as expected. In terms of causes of death, there were $4 / 51(7.8 \%)$ and 4/92 (4.3\%) cases with several types of neoplasms in the elderly and non-elderly groups, respectively $(p=0.38)$. Considering the benign prognosis of colorectal lesions resected by ESD, preoperative screening for comorbidities (especially for neoplasia) is important to achieve a better overall survival.

This study has several limitations worth noting. First, this was a single-center retrospective study. Second, few patients developed complications that required an emergent surgery. To accurately determine the risk of severe ESD-associated complications in elderly and non-elderly patients, a further large prospective and multicenter study is required. Third, we did not compare differences in outcomes between endoscopic mucosal resection (EMR) and ESD. According to a systematic review by De Ceglie et al. [27], compared to EMR, ESD showed a higher en bloc resection rate and lower recurrence rate, as well as a higher perforation rate (4.8\% in ESD and $0.9 \%$ in EMR). Additional disadvantages of ESD include the fact that it is a time-consuming procedure that requires a high level of skill. Therefore, for endoscopists who are not sufficiently familiar with ESD, piecemeal EMR for a large lesion is a reasonable alternative option. At present, there is an ongoing multicenter randomized clinical trial being conducted by Backs et al. [28], the MATILDA trial, which is evaluating the clinical efficacy and cost effectiveness of ESD and EMR.

\section{Conclusions}

Among the patients who underwent colorectal ESD in this study, there were no significant differences in clinical and 
histopathological characteristics between the elderly and nonelderly groups. ESD showed favorable short-term outcomes and disease-specific survival in both groups. However, the elderly group showed a lower overall survival rate. Considering the higher incidence of comorbidities in elderly patients, preoperative screening is essential for better longterm outcomes.

Compliance with ethical standards This study was approved by the ethics committee of the school of medicine, Niigata University, Japan. Written informed consent to participate was obtained from all patients who underwent colorectal ESD.

Open Access This article is distributed under the terms of the Creative Commons Attribution 4.0 International License (http:// creativecommons.org/licenses/by/4.0/), which permits unrestricted use, distribution, and reproduction in any medium, provided you give appropriate credit to the original author(s) and the source, provide a link to the Creative Commons license, and indicate if changes were made.

Open Access This article is distributed under the terms of the Creative Commons Attribution 4.0 International License (http:// creativecommons.org/licenses/by/4.0/), which permits unrestricted use, distribution, and reproduction in any medium, provided you give appropriate credit to the original author(s) and the source, provide a link to the Creative Commons license, and indicate if changes were made.

\section{References}

1. World Population Prospects, the (2015) Revision. Population Division, Department Economic and Social Affairs, United Nations http://esa.un.org/unpd/wpp/Download/Standard/Population/

2. Population Estimates by Age (5-year age Group) and sex (2015). Statistics Bureau, Ministry of Internal Affairs and Communications. http://www.stat.go.jp/english/data/jinsui/tsuki/index.htm. (Accessed Dec. 17, 2016)

3. She WH, Poon JT, Fan JK, Lo OS, Law WL (2013) Outcome of laparoscopic colectomy for cancer in elderly patients. Surg Endosc 27:308-312. doi:10.1007/s00464-012-2466-2

4. Nakamura T, Sato T, Miura H, Ikeda A, Tsutsui A, Naito M, Ogura N, Watanabe M (2014) Feasibility and outcomes of surgical therapy in very elderly patients with colorectal cancer. Surgical Laparoscopy, Endoscopy \& Percutaneous Techniques 24:85-88. doi:10.1097/SLE.0b013e3182a83477

5. Fujishiro M, Yahagi N, Kakushima N, Kodashima S, Muraki Y, Ono S, Yamamichi N, Tateishi A, Oka M, Ogura K, Kawabe T, Ichinose M, Omata M (2007) Outcomes of endoscopic submucosal dissection for colorectal epithelial neoplasms in 200 consecutive cases. Clinical Gastroenterology and Hepatology: the official clinical practice journal of the American Gastroenterological Association 5:678-683 . doi:10.1016/j.cgh.2007.01.006quiz 645

6. Saito Y, Uraoka T, Matsuda T, Emura F, Ikehara H, Mashimo Y, Kikuchi T, Fu KI, Sano Y, Saito D (2007) Endoscopic treatment of large superficial colorectal tumors: a case series of 200 endoscopic submucosal dissections (with video). Gastrointest Endosc 66:966973. doi:10.1016/j.gie.2007.02.053

7. Tamegai Y, Saito Y, Masaki N, Hinohara C, Oshima T, Kogure E, Liu Y, Uemura N, Saito K (2007) Endoscopic submucosal dissection: a safe technique for colorectal tumors. Endoscopy 39:418422. doi:10.1055/s-2007-966427
8. Tanaka S, Oka S, Kaneko I, Hirata M, Mouri R, Kanao H, Yoshida S, Chayama K (2007) Endoscopic submucosal dissection for colorectal neoplasia: possibility of standardization. Gastrointest Endosc 66:100-107. doi:10.1016/j.gie.2007.02.032

9. Yoshida N, Naito Y, Sakai K, Sumida Y, Kanemasa K, Inoue K, Morimoto Y, Konishi H, Wakabayashi N, Kokura S, Yagi N, Yanagisawa A, Yoshikawa T (2010) Outcome of endoscopic submucosal dissection for colorectal tumors in elderly people. Int $\mathbf{J}$ Color Dis 25:455-461. doi:10.1007/s00384-009-0841-9

10. Tamai N, Saito Y, Sakamoto T, Nakajima T, Matsuda T, Tajiri H (2012) Safety and efficacy of colorectal endoscopic submucosal dissection in elders: clinical and follow-up outcomes. Int J Color Dis 27:1493-1499. doi:10.1007/s00384-012-1514-7

11. Kudo S, Hirota S, Nakajima T, Hosobe S, Kusaka H, Kobayashi T, Himori M, Yagyuu A (1994) Colorectal tumours and pit pattern. J Clin Pathol 47:880-885

12. Kudo S, Rubio CA, Teixeira CR, Kashida H, Kogure E (2001) Pit pattern in colorectal neoplasia: endoscopic magnifying view. Endoscopy 33:367-373

13. Yamamoto H, Kawata H, Sunada K, Satoh K, Kaneko Y, Ido K, Sugano K (2002) Success rate of curative endoscopic mucosal resection with circumferential mucosal incision assisted by submucosal injection of sodium hyaluronate. Gastrointest Endosc 56:507512. doi:10.1067/mge.2002.128108

14. Fujishiro M, Yahagi N, Nakamura M, Kakushima N, Kodashima S, Ono S, Kobayashi K, Hashimoto T, Yamamichi N, Tateishi A, Shimizu Y, Oka M, Ogura K, Kawabe T, Ichinose M, Omata M (2006) Successful outcomes of a novel endoscopic treatment for GI tumors: endoscopic submucosal dissection with a mixture of highmolecular-weight hyaluronic acid, glycerin, and sugar. Gastrointest Endosc 63:243-249. doi:10.1016/j.gie.2005.08.002

15. Schlemper RJ, Riddell RH, Kato Y, Borchard F, Cooper HS, Dawsey SM, Dixon MF, Fenoglio-Preiser CM, Flejou JF, Geboes K, Hattori T, Hirota T, Itabashi M, Iwafuchi M, Iwashita A, Kim YI, Kirchner T, Klimpfinger M, Koike M, Lauwers GY, Lewin KJ, Oberhuber G, Offner F, Price AB, Rubio CA, Shimizu M, Shimoda T, Sipponen P, Solcia E, Stolte M, Watanabe H, Yamabe $\mathrm{H}$ (2000) The Vienna classification of gastrointestinal epithelial neoplasia. Gut 47:251-255

16. Toyonaga T, Man-i M, Fujita T, East JE, Nishino E, Ono W, Morita Y, Sanuki T, Yoshida M, Kutsumi H, Inokuchi H, Azuma T (2010) Retrospective study of technical aspects and complications of endoscopic submucosal dissection for laterally spreading tumors of the colorectum. Endoscopy 42 : 714-722. doi:10.1055/s-0030-1255654

17. Kim ES, Cho KB, Park KS, Lee KI, Jang BK, Chung WJ, Hwang JS (2011) Factors predictive of perforation during endoscopic submucosal dissection for the treatment of colorectal tumors. Endoscopy 43:573-578. doi:10.1055/s-0030-1256339

18. Takamaru H, Saito Y, Yamada M, So E, Kinjo Y, Otake Y, Sakamoto T, Nakajima T, Matsuda T (2016) Clinical impact of endoscopic clip closure of perforations during endoscopic submucosal dissection for colorectal tumors. Gastrointest Endosc. doi:10.1016/j.gie.2016.01.014

19. Taku K, Sano Y, Fu KI, Saito Y, Matsuda T, Uraoka T, Yoshino T, Yamaguchi Y, Fujita M, Hattori S, Ishikawa T, Saito D, Fujii T, Kaneko E, Yoshida S (2007) Iatrogenic perforation associated with therapeutic colonoscopy: a multicenter study in Japan. J Gastroenterol Hepatol 22:1409-1414. doi:10.1111/j.14401746.2007.05022.x

20. Tanaka S, Tamegai Y, Tsuda S, Saito Y, Yahagi N, Yamano HO (2010) Multicenter questionnaire survey on the current situation of colorectal endoscopic submucosal dissection in Japan. Digestive endoscopy : official journal of the Japan Gastroenterological Endoscopy Society 22(Suppl 1):S2-S8. doi:10.1111/j.14431661.2010.00952.x 
21. Chautard J, Alves A, Zalinski S, Bretagnol F, Valleur P, Panis Y (2008) Laparoscopic colorectal surgery in elderly patients: a matched case-control study in 178 patients. J Am Coll Surg 206: 255-260. doi:10.1016/j.jamcollsurg.2007.06.316

22. Akiyoshi T, Kuroyanagi H, Oya M, Konishi T, Fukuda M, Fujimoto Y, Ueno M, Yamaguchi T (2009) Short-term outcomes of laparoscopic rectal surgery for primary rectal cancer in elderly patients: is it safe and beneficial? Journal of Gastrointestinal Surgery : official journal of the Society for Surgery of the Alimentary Tract 13:16141618. doi:10.1007/s11605-009-0961-0

23. Jeong DH, Hur H, Min BS, Baik SH, Kim NK (2013) Safety and feasibility of a laparoscopic colorectal cancer resection in elderly patients. Annals of Coloproctology 29:22-27. doi:10.3393 /ac.2013.29.1.22

24. Tokuhara K, Nakatani K, Ueyama Y, Yoshioka K, Kon M (2016) Short- and long-term outcomes of laparoscopic surgery for colorectal cancer in the elderly: a prospective cohort study. International Journal of Surgery (London, England) 27:66-71. doi:10.1016/j. ijsu.2016.01.035

25. Niimi K, Fujishiro M, Kodashima S, Goto O, Ono S, Hirano K, Minatsuki C, Yamamichi N, Koike K (2010) Long-term outcomes of endoscopic submucosal dissection for colorectal epithelial neoplasms. Endoscopy 42:723-729. doi:10.1055/s-0030-1255675

26. Cong ZJ, Hu LH, Ji JT, Xing JJ, Shan YQ, Li ZS, Yu ED (2015) A long-term follow-up study on the prognosis of endoscopic submucosal dissection for colorectal laterally spreading tumors. Gastrointest Endosc. doi:10.1016/j.gie.2015.08.043

27. De Ceglie A, Hassan C, Mangiavillano B, Matsuda T, Saito Y, Ridola L, Bhandari P, Boeri F, Conio M (2016) Endoscopic mucosal resection and endoscopic submucosal dissection for colorectal lesions: a systematic review. Crit Rev Oncol Hematol 104:138155. doi:10.1016/j.critrevonc.2016.06.008

28. Backes Y, Moons LM, van Bergeijk JD, Berk L, Ter Borg F, Ter Borg PC, Elias SG, Geesing JM, Groen JN, Hadithi M, Hardwick JC, Kerkhof M, Mangen MJ, Straathof JW, Schroder R, Schwartz MP, Spanier BW, de Vos Tot Nederveen Cappel WH, Wolfhagen FH, Koch AD (2016) Endoscopic mucosal resection (EMR) versus endoscopic submucosal dissection (ESD) for resection of large distal non-pedunculated colorectal adenomas (MATILDA-trial): rationale and design of a multicenter randomized clinical trial. BMC Gastroenterol 16:56. doi:10.1186/s12876-016-0468-6 